Научная статья

УДК 615.27:616-009

DOI: $10.18101 / 2306-1995-2021-2-16-22$

\title{
МОЛЕКУЛЯРНЫЕ МЕХАНИЗМЫ ДЕЙСТВИЯ РАСТИТЕЛЬНЫХ АДАПТОГЕНОВ
}

\section{(C) Алексеева Эльвира Алексеевна}

кандидат медицинских наук, доцент, заведующая кафедрой анатомии и физиологии, Бурятский государственный университет имени Доржи Банзарова Россия, 670002, г. Улан-Удэ, ул. Октябрьская, 36а alecseevaelvira@mail.ru

\section{(C) Шантанова Лариса Николаевна}

доктор биологических наук, профессор, заведующая лабораторией безопасности биологически активных веществ,

Институт общей и экспериментальной биологии СО РАН

Россия, 670047, г. Улан-Удэ, ул. Сахьяновой, 6

alecseevaelvira@mail.ru

\begin{abstract}
Аннотация. На моделях острого и хронического эмоционального стресса изучена роль белков теплового шока (Hsp70) и белка p53 в реализации адаптогенного действия экстракта сухого астрагала перепончатого и комплексного растительного средства «Кардекаим», содержащих в качестве действующих веществ фенольные соединения и тритерпены. Курсовое профилактическое введение экстракта астрагала перепончатого в экспериментально-терапевтической дозе 50 мг/кг, кардекаима в дозе 100 мг/кг на фоне острого эмоционального стресса оказывает выраженное стресспротективное действие, препятствуя развитию признаков «триады Селье»: инволюции тимуса, гипертрофии надпочечников, эрозивным повреждениям слизистой желудка. На молекулярно-клеточном уровне стресспротективное действие испытуемых фитоэкстрактов сопровождается активацией синтеза Нsp70 в тимусе: астрагала в 2,6 раза; кардекаима на 56\% (p<0,05), а также выраженным ингибированием индукции Нsp70 в лейкоцитах стрессированных животных, подвергнутых тепловому шоку in vitro. На модели хронического эмоционального стресса курсовое профилактическое введение экстракта астрагала перепончатого не влияет, а кардекаима повышает уровень мРНК p53 в красном костном мозге на 50\%.
\end{abstract}

Ключевые слова: растительные адаптогены, острый эмоциональный стресс, хронический эмоциональный стресс, Hsp70, p53, астрагал перепончатый.

\section{Для цитирования}

Алексеева Э. А., Шантанова Л. Н. Молекулярные механизмы действия растительных адаптогенов // Вестник Бурятского государственного университета. Медицина и фармация. 2021. № 2. С. 16-22.

Адаптогены растительного происхождения эмпирически применяются в традиционных медицинских системах для укрепления физического и психического здоровья, улучшения защитных механизмов организма и увеличения продолжительности жизни [12]. Для понимания многовалентной фармакологической активности адаптогенов особый интерес представляют исследования молекулярных механизмов действия. Обнаружены молекулярные мишени, моду- 
ляция которых может отсрочить развитие стресс-ассоциированных заболеваний, включая возрастные нейродегенерации, сердечно-сосудистую патологию, метаболический синдром и др. [2; 4; 8; 9]. Одним из механизмов стресспротективного действия адаптогенов является активация синтеза молекулярных шаперонов (белков теплового шока) Нsp70 и др. [7]. Белок р53 синтезируется в организме в ответ на повреждение ДНК и другие изменения клеточной структуры. Он запускает процесс аутофагии, мембраноопосредованное «самопоедание» клетки, способствует очищению клетки от поврежденных органелл и других белковых субстанций [1]. В связи с этим необходимо выяснить роль белков Hsp и P-53 в реализации механизма действия растительных адаптогенов.

Целью проведенного исследования явилось определение роли белков Hsp70 и p53 в реализации адаптогенного действия растительных адаптогенов на моделях острого и хронического эмоционального стресса.

Материалы и методы. Кардекаим - экстракт сухой из четырех видов растительного сырья - корней и корневищ Inula helenium u Zingiber officinale, плодов Elletaria cardamonum и побегов Caragana spinosa, полученный по оригинальной методике на основе тибетской рецептурной прописи в Отделе биологически активных веществ ИОЭБ СО РАН, а также экстракт сухой, полученный из корней Astragalus membranaceus (Fischer) Bunge по запатентованной методике [5], они обладают выраженным адаптогенным действием на различных моделях стресса $[6 ; 13]$. Эксперименты проведены на крысах-самцах линии Wistar массой 160-180 г и на 24 белых мышах SHK обоего пола массой 12,5 г. Организация, порядок проведения исследований, содержание животных в условиях сертифицированного вивария ФГБУН «Институт общей и экспериментальной биологии» СО РАН соответствовало «Правилам лабораторной практики» (GLP) и приказу МЗ РФ № 199н от 01.04.2016 г. «Об утверждении Правил надлежащей лабораторной практики». Исследования проводились в соответствии с правилами «Европейской конвенции о защите позвоночных животных, используемых для экспериментальных или в иных научных целях», ETS № 123 от 18.03.1986 г. (Страсбург, 1986). Протокол экспериментальной апробации согласован с этической комиссией Института общей и экспериментальной биологии СО РАН (протокол № 1 от 15.01.2016). Модель острого эмоционального стресса воспроизводили методом водной иммерсии путем однократного помещения животных в клетку с водой $\left(22^{\circ} \mathrm{C}\right)$ на 30 минут и 4 часа. Через два часа после стрессорного воздействия животных декапитировали под легким эфирным наркозом и определяли степень гипертрофии надпочечников, количество эрозий слизистой оболочки желудка, а также определяли массу тимуса, который затем замораживали и хранили в замороженном виде при $-70{ }^{\circ} \mathrm{C}$ до электрофореза. Оценивали синтез Нsp-70 в тимусе и лейкоцитах (индуцированный тепловым шоком) методом вестерн-блот анализа с использованием антител к Hsp-70, реактивов и оборудования фирмы «Bio-Rad» (USA). Количественная обработка полученных иммуноблотов проводилась с помощью компьютерной программы Photoshop. Животные опытной группы 1 получали per os в течение 7 дней до эксперимента водный раствор экстракта сухого астрагала перепончатого 50 мг/кг, опытной группы 2 - водный раствор кардекаима 
100 мг/кг за 1 ч до кормления. Животным референтной группы вводили препарат сравнения - деалкоголизированный экстракт элеутерококка в объеме 5 мл/кг по аналогичной схеме. Контрольной группе аналогично вводили дистиллированную воду. Хронический иммобилизационный стресс моделировали 4-часовым подвешиванием за шейную складку в течение 10 дней. Исследуемые препараты вводили профилактически в течение 7 дней до и 10 дней в течение эксперимента за 1 час до стрессорного воздействия. На 10 день сразу после стрессорного воздействия произвели забой мышей и выделение красного костного мозга из костей задних конечностей, выделение мРНК проводили с помощью набора «Рибо-преп», получали кДНК на матрице мРНК, используя комплект готовых реагентов «Реверта-L», ПЦР-PВ проводили на приборе iCycler iQ5 real-time PCR (BioRad, Германия). Для оценки числа копий мРНК применялся $\Delta \mathrm{Ct}$-метод относительного определения количества по формуле $(1 / 2) \Delta \mathrm{Ct}$, где $\Delta \mathrm{Ct}=\mathrm{Ct}(\mathrm{p} 53)-\mathrm{Ct}(\mathrm{GAPDH})$. Статистическую обработку полученных данных проводили с использованием t-критерия Стьюдента.

Результаты и их обсуждение. Курсовое профилактическое введение экстракта кардекаима 100 мг/кг 7 дней лабораторным крысам перед острым иммобилизационным стрессом оказывает выраженное стресспротективное действие, препятствуя развитию признаков «триады Селье»: инволюции тимуса $(40 \%)$, язвенных повреждений слизистой желудка (в 5 раз) и в меньшей степени - гипертрофии надпочечников $(\mathrm{p} \leq 0,05)$, полученный эффект не уступает препарату сравнения - экстракту элеутерококка (табл. 1).

Таблица 1

Влияние растительных средств на выраженность признаков «триады Селье» при остром эмоциональном стрессе $(\mathrm{M} \pm \mathrm{m})$

\begin{tabular}{|c|c|c|c|c|}
\hline \multirow[t]{2}{*}{ Группы животных } & \multirow[t]{2}{*}{$\mathrm{n}$} & \multicolumn{2}{|c|}{$\begin{array}{l}\text { Относительный вес, } \\
\text { мг/100 г массы }\end{array}$} & \multirow{2}{*}{$\begin{array}{c}\text { Количество деструк- } \\
\text { ций в слизистой же- } \\
\text { лудка на одно живот- } \\
\text { ное }\end{array}$} \\
\hline & & $\begin{array}{c}\text { надпочеч- } \\
\text { ников }\end{array}$ & тимуса & \\
\hline Интактная (дист.вода) & 6 & $17,3 \pm 0,83$ & $\begin{array}{c}242,6 \pm \\
9,18 \\
\end{array}$ & 0,0 \\
\hline Контрольная 1 (стресс) & 6 & $\begin{array}{l}22,1 \pm \\
1,42^{*}\end{array}$ & $\begin{array}{l}173,4 \pm \\
19,53 *\end{array}$ & $3,2 \pm 0,52 *$ \\
\hline $\begin{array}{l}\text { Опытная } 1 \text { (стресс+ карде- } \\
\text { каим) }\end{array}$ & 6 & $\begin{array}{l}19,6 \pm \\
1,14 * *\end{array}$ & $\begin{array}{l}213,1 \pm \\
18,12 * *\end{array}$ & $1,3 \pm 0,73 * *$ \\
\hline $\begin{array}{l}\text { Опытная } 2 \text { (стресс+ астра- } \\
\text { гал) }\end{array}$ & 6 & $\begin{array}{l}17,5 \pm \\
0,11^{* *}\end{array}$ & $\begin{array}{c}231,7 \pm 13,4 \\
1 * *\end{array}$ & $1,1 \pm 0,43 * *$ \\
\hline $\begin{array}{l}\text { Опытная } 3 \text { (стресс+элеуте- } \\
\text { рококк) }\end{array}$ & 6 & $\begin{array}{c}20,3 \pm 2,19 * \\
*\end{array}$ & $\begin{array}{c}234,7 \pm 23,7 \\
7 * *\end{array}$ & $1,1 \pm 0,10^{* *}$ \\
\hline
\end{tabular}

Примечание: * здесь и далее: $\mathrm{p}<0,05$ по сравнению с интактом (дист. вода); ** $\mathrm{p}<0,05$ по сравнению с контролем; $\mathrm{n}$ - число животных. 
Курсовое превентивное введение экстракта сухого астрагала перепончатого также повышает устойчивость организма к эмоциональному стрессу, о чем свидетельствует уменьшение степени гипертрофии надпочечников на $20 \%$, увеличение относительной массы тимуса на $34 \%$, а также уменьшение количества эрозий слизистой желудка крыс в 2,8 раза по сравнению с показателями животных контрольной группы $(\mathrm{p} \leq 0,05)$.

Как следует из таблицы 2 , курсовое введение кардекаима интактным животным не оказывает влияния на уровень Hsp70 в тимусе, в то же время введение кардекаима на фоне стресса повышает его содержание на $56 \%$ по сравнению с данными контрольной группы. На фоне курсового введения астрагала перепончатого интактным животным уровень Нsp70 в тимусе повысился на $45 \%(\mathrm{p}<0,05)$, еще более значительное повышение уровня Нsp70 в 2,6 раза по сравнению с контролем обнаружилось при введении испытуемого средства стрессированным животным. У опытных групп, получавших испытуемые средства, содержание Hsp-70 в лейкоцитах после теплового шока снизилось почти в 3 раза по сравнению с данными крыс в контроле. Таким образом, экспериментально установлены различия в отношении индукции Нsp-70 под влиянием кардекаима in vivo и in vitro (табл. 2).

Таблица 2

Влияние кардекаима и ЭСАП на базальный уровень Нsp70 в тимусе и индуцированный тепловым шоком синтез Hsp70 в лейкоцитах на модели острого эмоционального стресса; ОДЕ, $(\mathrm{M} \pm \mathrm{SD})$

\begin{tabular}{|l|c|c|}
\hline \multirow{2}{*}{ Группа } & \multicolumn{2}{|c|}{ Содержание Нsр-70 } \\
\cline { 2 - 3 } & в тимусе & $\begin{array}{c}\text { в лейкоцитах после } \\
\text { теплового шока }\end{array}$ \\
\hline Интактная (дист.вода) & $5,5 \pm 0,55$ & $0,7 \pm 0,04$ \\
\hline Интактная (кардекаим) & $5,1 \pm 0,54$ & $0,5 \pm 0,03$ \\
\hline Интактная (астрагал) & $8,1 \pm 1,26$ & $0,8 \pm 0,11$ \\
\hline Контрольная (стресс) & $4,8 \pm 0,58$ & $2,9 \pm 1,32^{*}$ \\
\hline Опытная 1 (стресс+кардекаим) & $9,8 \pm 1,16^{* *}$ & $1,0 \pm 0,16^{* *}$ \\
\hline Опытная 2 (стресс+астрагал) & $13,0 \pm 2,04^{* *}$ & $1,0 \pm 0,13^{* *}$ \\
\hline
\end{tabular}

Выявлено, что хроническое стрессорное воздействие в виде иммобилизационного стресса (4-часовое подвешивание за шейную складку в течение 10 дней) вызывает у мышей контрольной группы достоверное снижение на $36 \%$ уровня мРНК p53 в красном костном мозге животных $(\mathrm{P}=0,0047)$ по сравнению с аналогичными данными интактных мышей.

Превентивное курсовое введение тетрафитона нормализует данный показатель, о чем свидетельствует повышение уровня мРНК р53 на 50\% по сравнению с данными в контрольной группе животных. Достоверных отличий в уровне мРНК р53 на фоне введения астрагала не обнаружено (рис. 1). Таким образом установлено, что профилактическое курсовое введение кардекаима 100 мг/кг на фоне 10 -дневного 4-часового иммобилизационного стресса вызывает активацию экспрессии гена р53 в красном костном мозге животных. 


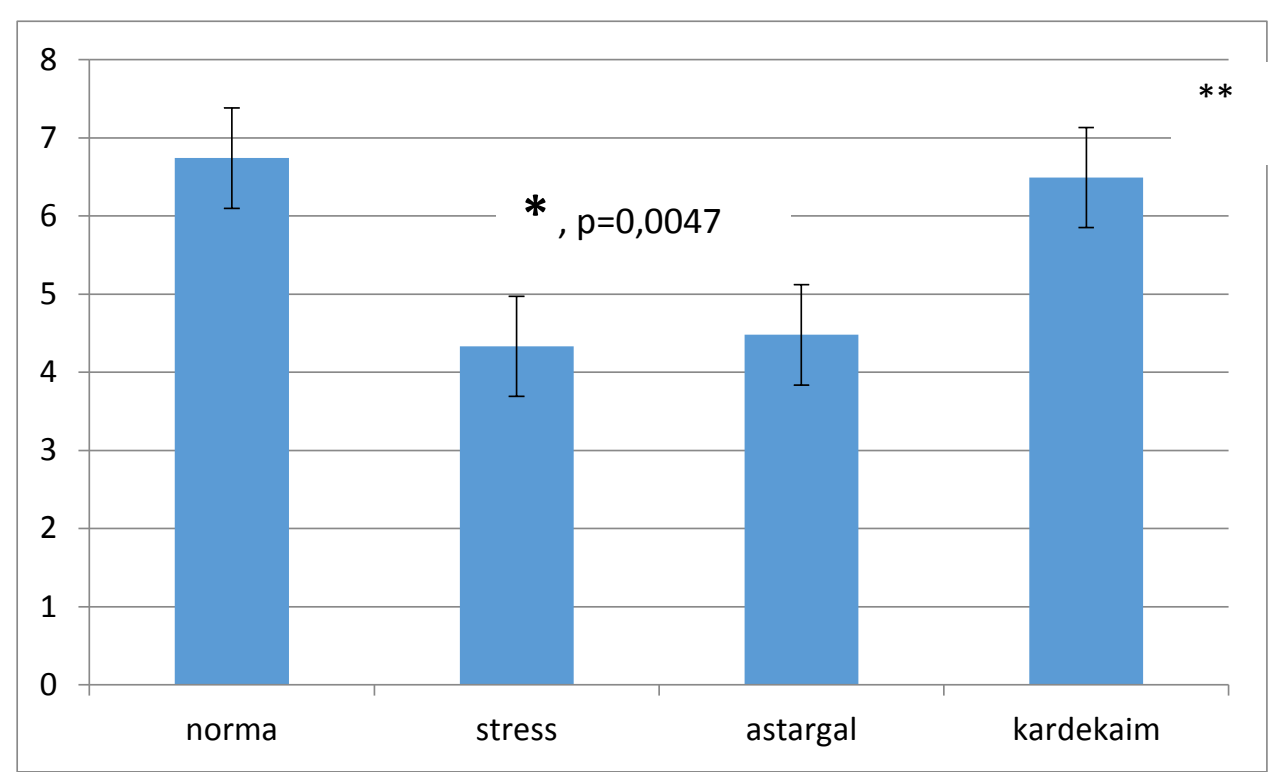

Рис. 1. Влияние кардекаима и астрагала перепончатого на уровень мРНК р53 на модели хронического стресса

Эмоциональный стресс вызывает реверберацию возбуждения в эмоциогенных лимбико-ретикулярных структурах головного мозга, оказывающих непрерывное нисходящее нервное и гуморальное влияние на периферические органы-мишени посредством взаимодействия с рецепторами клеток, особенно метаботропных, активирующих внутриклеточные сигнальные каскады и факторы транскрипции, которые индуцируют экспрессию протективных белков [10]. Под действием стресса происходит перегрузка системы протеостаза неправильно свернутыми белками, что приводит к гибели клеток и повреждению органов и преждевременному старению [9]. Нами обнаружено, что профилактическое курсовое введение разработанных растительных экстрактов кардекаима и астрагала перепончатого стрессированным животным достоверно повышает уровень молекулярных шаперонов Hsp70 в тимусе. Нsp70, как известно, способен ограничивать повреждения за счет ренатурации белков, поврежденных в результате стресса, дезагрегации аномальных белковых молекул, предотвращая, по-видимому, развитие инволюции тимуса и других внутренних органов [11; 12]. Причем если комплексное средство «Кардекаим» показало мягкое индуцирующее действие, введение астрагала стрессированным животным вызвало индукцию Hsp70 в 2,6 раза. Интересно, что в лейкоцитах стрессированных животных, подвергнутых тепловому шоку в условиях in vitro, обнаружена многократная индукция белка Hsp70, причем на фоне введения испытуемых средств индуцибельность значительно снижается, практически до уровня показателя интактных животных. Мы предполагаем, что активация экспрессии белков Нsp-70 в клетках является молекулярно-клеточным механизмом стресспротективного действия указанных фитоадаптогенов, это обусловлено наличием в их составе фенольных соединений и летучих терпеноидов. Так, в экстракте астрагала перепончатого присутствуют флавоноиды: изофлавоны — кали- 
козин, каликозин-7-О-глюкозид и формононетин, а в составе фенольных соединений кардекаима установлено наличие представителей групп фенилпропаноидов, флавоноидов и арилгептаноидов. На модели хронического эмоционального стресса установлено, что профилактическое курсовое введение кардекаима вызывает активацию экспрессии белка р53 в красном костном мозге животных, который также участвует в утилизации поврежденных белков, способствует очищению клетки от поврежденных органелл и других белковых субстанций, обеспечивая тем самым выживание здоровых клеток [1]. Поскольку известно, что снижение способности индуцировать Нsp70 в нейронах и нейроглии, в скелетной и сердечной мышцах связано со старением, ингибирование экспрессии Hsp70 обнаружено при болезни Альцгеймера и приводит к накоплению бляшек агрегированного амилоидного пептида, а также возрастное снижение экспрессии Нsp70 в печени обусловливает снижение детоксицирующей функции печени у пожилых людей [2-4, 8-10]. Наличие выявленной нами активности кардекаима и астрагала перепончатого позволяет рекомендовать испытуемые фитоэкстракты для профилактики негативных последствий стресса, в первую очередь у пожилых пациентов (антиэйдж-терапия).

\section{Литература}

1. Дубиков А. И. Белок Р53: новая жизнь старой молекулы. Ч. 1. Обзоры // Научнопрактическая ревматология. 2010. № 3. С. 52-58. Текст: непосредственный.

2. Роль естественных процессов старения в возникновении и патогенезе болезней, связанных с аномальным накоплением белковых агрегатов / Н. С. Ильинский, С. В. Нестеров, Е. И. Шестоперова [и др.] // Биохимия. 2021. Т. 86, № 3. С. 324-340. Текст: непосредственный.

3. Максимович Н. Е., Бонь Е. И. Белки теплового шока. Свойства. Роль в адаптации. Методические подходы к определению // Биомедицина. 2020. № 16(2). С. 60-67. Текст: непосредственный.

4. Роль белка теплового шока HSP70 в развитии сердечно-сосудистой патологии (обзор литературы) / А. В. Наумов, Т. В. Прокофьева, О. С. Полунина, Л. В. Сароянц // Вестник новых медицинских технологий. 2020. № 6. С. 133-139. Текст: непосредственный.

5. Способ получения средства, обладающего адаптогенным действием: пат. 2582952 Рос. Федерация // Д. Н. Оленников, Г. В. Чехирова, Л. М. Танхаева [и др.]; заявитель и патентообладатель ИО и ЭБ СО РАН // Бюл. № 12. 27.04.2016. Текст: непосредственный.

6. Стресс-протекторная активность комплексного растительного средства «Кардекаим» на модели иммобилизационного стресса / Л. Н. Шантанова, Э. А. Алексеева, А. А. Торопова [и др.] // Экспериментальная и клиническая фармакология. 2015. Т. 78, № 9. С. 27-31. Текст: непосредственный.

7. Asea A., Kaur P., Panossian A., Wikman K. G. Evaluation of molecular chaperones Hsp 72 and neuropeptide $\mathrm{Y}$ as characteristic markers of adaptogenic activity of plant extracts // Phytomed. 2013. Vol. 20. P. 1323-1329.

8. Gupta A., Bansal A., Hashimoto-Torii K. HSP70 and HSP90 in neurodegenerative diseases. Neurosci. Lett. 2020. No. 18. P. 716-720.

9. Leak R. K. Heat shock proteins in neurodegenerative disorders and aging // J. Cell. Commun. Signal. 2014. No. 8(4). P. 293-310.

10. McEwen BS. Physiology and neurobiology of stress and adaptation: central role of the brain // Physiol Rev. 2007. No. 87(3). P. 873-904. 
11. Panossian A. Effects of adaptogens on the central nervous system and the molecular mechanisms associated with their stress-protective activity // Pharmaceuticals. 2010. № 3. P. 188-224.

12. Panossian A. Understanding adaptogenic activity: specificity of the pharmacological action of adaptogens and other phytochemicals //Annals of the New York Academy of Sciences. 2017. No. 1401(1). P. 49-64.

13. Systematic Review of Phytochemistry, Pharmacology and Pharmacokinetics on Astragali Radix: Implications for Astragali Radix as a Personalized Medicine / G. Zhenzhen, L.Yanmei, K. Muyan [et al.] // Int. J. Mol. Sci. 2019. Vol. 20(6). P. 1463.

Статья поступила в редакичи 09.10.2021; одобрена после рецензирования 25.11.2021; принята к публикации 22.12.2021.

\section{MOLECULAR MECHANISMS OF THE EFFECT OF PLANT ADAPTOGENS}

\section{Elvira A. Alekseeva}

Cand. Sci. (Medicine), A/Prof.,

Head of Anatomy and Physiology Department,

Dorzhi Banzarov Buryat State University

36a Oktyabrskaya St., Ulan-Ude 670000, Russia

alecseevaelvira@mail.ru

\section{Larisa N. Shantanova}

Dr. Sci. (Biol.), Prof.,

Head of Laboratory for Safety of Biologically Active Substances,

Institute of General and Experimental Biology SB RAS

6 Sakhyanovoy St., Ulan-Ude 670047, Russia

shantanova@mail.ru

Abstract. We have studied the role of heat shock proteins (HSP70) and p53 in the adaptogenic effect of the extract from Astragalus membranaceus (Fischer) Bunge and a complex herbal remedy "Kardekaim", containing flavonoids and triterpenes as active ingredients, on the models of acute and chronic mental stress. Course prophylactic administration of Astragalus membranous extract at an experimental therapeutic dose of $50 \mathrm{mg} / \mathrm{kg}$, and "Kardekaim" at a dose of $100 \mathrm{mg} / \mathrm{kg}$ has a pronounced stressprotective effect, prevent the symptoms of Selye's triad: enlargement of the adrenal glands, atrophy of the lymphatic system including the thymus, and peptic ulcers of the stomach and duodenum. At the cellular level, the stress-protective effect of Astragalus is accompanied by the activation of HSP70 synthesis in the thymus in 2.6 times, and "Kardekaim" by $56 \%(\mathrm{p}<0.05)$. We also observed a pronounced inhibition of HSP70 induction in leukocytes of stressed animals subjected to heat shock in vitro. The prophylactic administration of Astragalus membranous extract does not effect on the chronic mental stress, but "Kardekaim" increases the level of p53 mRNA in the red bone marrow by $50 \%$.

Keywords: plant adaptogens, acute mental stress, chronic mental stress, HSP, p53, Astragalus membranaceus.

\section{For citation}

Alekseeva E. A., Shantanova L. N. Molecular Mechanisms of the Effect of Plant Adaptogens. Bulletin of Buryat State University. Medicine and Pharmacy. 2021; 2: 16-22 (In Russ.).

The article was submitted 29.10.2021; approved after reviewing 25.11.2021; accepted for publication 22.12.2021. 